\title{
Effect of Hydrogen Content and Dilution on Laminar Burning Velocity and Stability Characteristics of Producer Gas-Air Mixtures
}

\author{
V. Ratna Kishore, M. R. Ravi, and Anjan Ray \\ Department of Mechanical Engineering, Indian Institute of Technology Delhi, New Delhi 110 016, India \\ Correspondence should be addressed to Anjan Ray, raya@mech.iitd.ernet.in
}

Received 5 September 2007; Revised 27 March 2008; Accepted 5 June 2008

Recommended by Lea-Der Chen

Producer gas is one of the promising alternative fuels with typical constituents of $\mathrm{H}_{2}, \mathrm{CO}, \mathrm{CH}_{4}, \mathrm{~N}_{2}$, and $\mathrm{CO}_{2}$. The laminar burning velocity of producer gas was computed for a wide range of operating conditions. Flame stability due to preferential diffusional effects was also investigated. Computations were carried out for spherical outwardly propagating flames and planar flames. Different reaction mechanisms were assessed for the prediction of laminar burning velocities of $\mathrm{CH}_{4}, \mathrm{H}_{2}, \mathrm{H}_{2}-\mathrm{CO}$, and $\mathrm{CO}-\mathrm{CH}_{4}$ and results showed that the Warnatz reaction mechanism with $\mathrm{C} 1$ chemistry was the smallest among the tested mechanisms with reasonably accurate predictions for all fuels at 1 bar, $300 \mathrm{~K}$. To study the effect of variation in the producer gas composition, each of the fuel constituents in ternary $\mathrm{CH}_{4}-\mathrm{H}_{2}$ - $\mathrm{CO}$ mixtures was varied between 0 to $48 \%$, while keeping diluents fixed at $10 \% \mathrm{CO}_{2}$ and $42 \% \mathrm{~N}_{2}$ by volume. Peak burning velocity shifted from $\phi=1.6$ to 1.1 as the combined volumetric percentage of hydrogen and CO varied from $48 \%$ to $0 \%$. Unstable flames due to preferential diffusion effects were observed for lean mixtures of fuel with high hydrogen content. The present results indicate that $\mathrm{H}_{2}$ has a strong influence on the combustion of producer gas.

Copyright ( $) 2008$ V. Ratna Kishore et al. This is an open access article distributed under the Creative Commons Attribution License, which permits unrestricted use, distribution, and reproduction in any medium, provided the original work is properly cited.

\section{INTRODUCTION}

Synthetic gas, often called syngas or producer gas, can be generated from natural gas, petroleum, gasification of coal, biomass, or even organic wastes. The availability and flexibility of feedstock for production of producer gas make it a potential future fuel. Producer gas mainly consists of combustible gases, namely, hydrogen, carbon monoxide, and traces of methane and diluents, namely, carbon dioxide and nitrogen. Producer gas is used to generate hydrogen for various applications and as a source of carbon monoxide, which is used for carboxylation reactions [1]. Recently, producer gas has also been directly used as a gas turbine fuel in integrated coal-gasification combined cycle (IGCC) power plants, which provide cost-effective and environmentally sound options for meeting future coal-utilizing power generation needs [2]. Compositions and calorific values of producer gas vary widely depending on raw materials and gasifier types. Gaseous fuel, produced in various gasifiers, has a calorific value of $4-13 \mathrm{MJ} / \mathrm{m}^{3}$ at STP conditions.
Laminar burning velocity, which is a fundamental property of any combustible mixture, is useful in the determination of its combustion rates and hence is a key parameter in the design of combustion systems. The stability of these flames with respect to preferential diffusion is often characterized by their Markstein lengths. Experimental data for laminar burning velocity values generated by various research groups almost until the turn of this millennium were not consistent with each other, primarily because the effect of flame stretch rate was not taken into account. Hence, it is essential to always quote a stretch-free value of the laminar burning velocity. Any flame configuration chosen for the measurement of burning velocity should subject the flame to a known stretch rate that is uniform over the flame surface. This would help in determining the stretchfree burning velocity by extrapolation. Spherical flames propagating at constant pressure fulfil these requirements well and hence were used in the present investigation.

Mishra et al. [3] developed a code for spherical inwardly and outwardly propagating premixed flames to determine 
the effect of stretch. They showed that a single step mechanism is not good for accurate computation of burning velocities. Bradley et al. [4] developed a code for spherical laminar flame propagation in three modes for methaneair mixtures: explosion (outwardly propagating), implosion (inwardy propagating), and stationary spherical flames to determine burning velocities, the effect of stretch, and hence the unstretched burning velocity. Sun et al. [5] presented computational results for spherical inwardly and outwardly propagating flames, planar flames, and counter flow premixed flames using Sandia National Laboratories' PREMIX and OPPDIF codes [6] for the dynamics of weakly stretched flames and also for quantitative description of the nonequidiffusion effect on flame stretch.

Vagelopoulos and Egolfopoulos [7] studied the influence of hydrogen and methane addition on the propagation and extinction of CO-air flames using the counterflow premixed flame configuration. Vagelopoulos and Egolfopoulos [8] have reported the direct experimental determination of unstretched laminar burning velocity with the flame impinging onto a plate at various distances from the burner exit. They measured burning velocities for methane, ethane, and propane at ultra-low strain rates.

Faeth et al. [9-13] measured laminar burning velocity along with stretch correction and Markstein numbers to understand stability using a schlieren apparatus and high-speed photography for constant pressure spherical outwardly propagating flames of methane, hydrogen, and hydrogen/carbon monoxide with air. They also computed the laminar burning velocity using RUN1DL [14] and PREMIX [6] and discussed the stretch/preferential diffusion interactions based on the computed flame structures.

The present work involves the computational determination of laminar burning velocity of producer gas-air mixtures using the RUN1DL computational code developed by Rogg and Wang [14] and Sandia National Laboratory's PREMIX [6]. The prime objective is to study the effect of hydrogen content and diluent content in the producer gas fuel mixture on the laminar burning velocity and flame stability. Different reaction mechanisms, namely, the $\mathrm{C} 1$ and C2 reaction mechanisms of Warnatz et al. [15] and the GRI Mech 3.0 reaction mechanism [16] have been evaluated for computing laminar burning velocities of pure methane, pure hydrogen, $\mathrm{H}_{2}-\mathrm{CO}$ and $\mathrm{CO}-\mathrm{CH}_{4}$ mixtures burning in air, by comparing the results against published experimental data. The purpose of such an exercise was to choose a relatively small mechanism which can be suitably used for computation for such mixtures properly and for which computational effort is reasonable. Hence, other large mechanisms like Konnov release 0.5 [17] and the San Diego mechanism [18] were not considered. Computations for producer gas, which is represented as ternary mixtures of $\mathrm{CO}-\mathrm{CH}_{4}-\mathrm{H}_{2}$ with diluents $\mathrm{N}_{2}$ and $\mathrm{CO}_{2}$ with different compositions, have also been carried out. A systematic study of the variations in burning velocity and equivalence ratio at peak burning velocity was carried out. The stability of the flames was studied using both a Markstein number and an effective Lewis number. The latter is found to predict the occurrence of instabilities for different mixtures.

\section{COMPUTATIONAL CODES}

Unsteady numerical simulations of outwardly propagating spherical laminar flames were performed using the computational code RUN-1DL by Rogg and Wang [14]. RUN1DL employs the Euler extrapolation scheme. In order to tackle the stiffness of the governing equations, which are introduced through the chemical source terms and profiles of quantities involved in combustion processes which typically exhibit steep gradients and strong curvature, the use of adaptive methods is resorted to, so that control of both temporal and spatial discretization errors is possible. The calculations for unstretched (planar) flames were carried out using the steady, one-dimensional laminar premixed flame code PREMIX [6]. The latter computations were performed for the sake of comparison of the unstretched burning velocities obtained by extrapolation of the results of RUN1DL simulations to zero stretch limit.

\section{CALCULATION OF STRETCH RATE}

The flame stretch rate, $\kappa$, at a point on a flame surface is the time rate of change of an infinitesimally small element of area A surrounding the point, normalized by the area. For the spherically symmetric outwardly propagating flames under consideration, the total stretch rate was shown to be [4]

$$
\kappa=2 \frac{S_{n}}{r_{u}}
$$

where $S_{n}$ is flame speed and $r_{u}$ is flame radius. The flame position was obtained by tracking a particular isotherm and then flame speed and burning velocity were calculated. Unstretched burning velocity $\left(S_{L_{\infty}}\right)$ was obtained by linear extrapolation of stretched burning velocity to zero stretch using

$$
S_{L}=S_{L \infty}-L \kappa
$$

Here, $L$ is the Markstein length. Two dimensionless numbers were defined to conveniently characterise the effect of stretch: the Karlovitz number $\left(\mathrm{Ka}=\kappa \delta_{D} / S_{L}\right)$ and the Markstein number $\left(\mathrm{Ma}=L / \delta_{D}\right)$ [9]. The Karlovitz number represents the ratio of characteristic flame residence time to the characteristic flame stretch time, $\kappa^{-1}$. The Markstein number represents the sensitivity of laminar burning velocities to flame stretch and can be either positive (stable flames) or negative (unstable flames) [19]. For the present work, the characteristic flame thickness $\delta_{D}\left(=D_{u} / S_{L}\right)$ was based on a characteristic mass diffusivity $\left(D_{u}\right)$ and the laminar burning velocity of the stretched flame, in accordance with the approach followed in [9]. Putting the above relations into (2) and rearranging will yield

$$
\frac{S_{L \infty}}{S_{L}}=1+\text { Ma Ka. }
$$

\section{CHEMICAL REACTION MECHANISM}

Two detailed chemical reaction mechanisms due to Warnatz et al. [15], one consists of only C1 chemistry consists 
of 16 reactive species and 97 chemical reactions (referred to in the present paper as $\mathrm{C} 1$ mechanism) and another mechanism consists of C1-C2 chemistry, consists of 23 reactive species and 140 chemical reactions (referred to as C2 mechanism), were used in the present work in the RUN1DL code. These mechanisms have smaller sets of reactions and are widely used at 1 bar pressure. GRIMech 3.0 [16] reaction mechanism with 53 species and 325 reactions is an optimised reaction mechanism available for methane combustion - it is used with the PREMIX code. Computation of the spherical outwardly propagating flame for the stoichiometric methane-air mixture with GRI-Mech 3.0 using RUN1DL even up to a small flame radius of $4 \mathrm{~cm}$ required a computation time up to 50 hours on an Intel P4based $3 \mathrm{GHz}$, 32-bit computer. Thus, in the computation of spherically expanding flames, this mechanism was not used. Also, other large mechanisms like San Diego mechanism [18] and Konnov release 0.5 [17] were not considered when using RUN1DL. On PREMIX, the computational time using this mechanism is relatively shorter, and hence it was decided to perform the PREMIX simulations using GRI Mech 3.0, while the RUN1DL calculations were confined to the Warnatz C1 and C2 mechanisms. It has however been verified for specific cases that the predicted unstretched burning velocities from both codes using the same mechanism are nearly identical.

\section{ASSESSMENT OF SUITABILITY OF REACTION MECHANISMS FOR PRESENT SIMULATIONS}

The two Warnatz [15] reaction mechanisms have been evaluated for their suitability in accurately determining the laminar burning velocity of various mixture combinations using experimental data in the literature. This was done by comparing the computationally obtained burning velocities for outwardly propagating spherical flames using these mechanisms in RUN1DL with published data from the literature as well as results obtained for planar flames using PREMIX.

The adaptive grid parameters (GRAD and CURV) which place more grid points at steep gradients and sharp curvatures, respectively, are so chosen that the number of grid points in the reaction zone was more than 50 [4] to ensure grid independent results. The effects of these grid parameters on the predicted value of laminar burning velocity of stoichiometric methane-air mixture are shown in Table 1. It is clear that the effect of changing GRAD from 0.1 to 0.01 on burning velocity is very little. Hence, a GRAD value of 0.01 and a CURV value of 1.5 were chosen for use in all the computations presented in this paper.

For all computations, the cold boundary was taken at $12 \mathrm{~cm}$ radius. The burnt gas temperature obtained from the above computations was $2240 \mathrm{~K}$ for stoichiometric methaneair mixture at 1 bar and $300 \mathrm{~K}$, which is equal to the adiabatic equilibrium temperature, showing that the extent chosen for the computational domain was sufficient in this case.

The suitability of various reaction mechanisms used in the present work was assessed by comparing the laminar burning velocities predicted using these mechanisms against experimental data available in the literature. As a first step,
TABLE 1: Effect of grid parameters on burning velocity for stoichiometric methane-air mixture at 1 bar and $300 \mathrm{~K}$.

\begin{tabular}{cccc}
\hline $\begin{array}{l}\text { Adaptive grid parameters } \\
\text { GRAD }\end{array}$ & CURV & $\begin{array}{c}\text { No. of } \\
\text { grid points }\end{array}$ & $\begin{array}{c}\text { Burning velocity } \\
(\mathrm{cm} / \mathrm{s})\end{array}$ \\
\hline 0.5 & 1.5 & 70 & 36.7 \\
0.1 & 1.5 & 120 & 34.9 \\
0.01 & 1.5 & 190 & 34.8 \\
\hline
\end{tabular}

computations were carried out for pure gaseous fuels, such as methane and hydrogen burning in air at 1 bar with unburnt gas temperature $300 \mathrm{~K}$, since chemical kinetics and experimental data on laminar burning velocity are well established for these mixtures.

For methane-air, agreement of computational results with Warnatz $\mathrm{C} 1$ chemistry with the available experimental data for a $\phi$ range of $0.7-1.2$ was better than those with Warnatz C2 chemistry and GRI-Mech 3.0. For very rich mixtures $(\phi=1.3)$, however, $\mathrm{C} 1$ chemistry predicts burning velocity lower than experiments because for rich mixtures the $\mathrm{CH}_{3}$ radical would combine to give $\mathrm{C}_{2}$ radicals. Thus, $\mathrm{C} 2$ chemistry is expected to work better for such mixtures than $\mathrm{C} 1$ chemistry. For hydrogen-air mixture predictions using the $\mathrm{C} 1$ mechanism in RUN1DL up to an equivalence ratio of 3.0 are in good agreement with experimental data, as well as predictions using GRI-Mech 3.0 mechanism in PREMIX.

The Warnatz $\mathrm{C} 1$ mechanism produces reasonably accurate results for methane-air, and also hydrogen-air mixtures at $1 \mathrm{bar}, 300 \mathrm{~K}$. In order to evaluate the accuracy of predictions using this mechanism when $\mathrm{CO}$ is also present in the combustible mixture, as well as when more than one combustible constituent is present in the mixture, simulation results at the same initial pressure, and temperature for binary fuel mixtures are compared with the experimental results available in the literature. Computations were performed for the combustion of binary mixtures of $\mathrm{CO}-\mathrm{H}_{2}$ and $\mathrm{CH}_{4}-\mathrm{CO}$ in air.

Only one published work (Vagelopoulos and Egolfopoulos [7], using the counter-flow premixed flame technique) is available for unstretched burning velocities of $\mathrm{CH}_{4}-\mathrm{CO}$ mixtures burning in air at 1 bar pressure with unburnt gas temperature $300 \mathrm{~K}$. Simulations were performed for the compositions tested in [7]. The results are shown in Figure 1. The format of presentation follows that of [7], where the abscissa is the mole fraction of $\mathrm{CH}_{4}$ in the mixture, and curves are plotted for different mole fractions of the fuel $\left(\mathrm{CH}_{4}-\mathrm{CO}\right)$ in the mixture. The predictions are within the experimental uncertainties mentioned in [7].

Computations were done at 1 bar pressure and unburnt gas temperature $300 \mathrm{~K}$ for fuel mixtures of composition $5 \% \mathrm{H}_{2}-95 \% \mathrm{CO}$ and $50 \% \mathrm{H}_{2}-50 \% \mathrm{CO}$. The thermal diffusion effect was included in these computations [14]. Predictions of unstretched laminar burning velocities for these mixtures with RUN1DL using the Warnatz C1 mechanism for spherically expanding flames are plotted in Figure 2 and compared with spherically expanding flame measurements by Hassan et al. [10], McLean et al. [20], and Sun et al. [21] and those obtained with PREMIX using GRI-MECH 


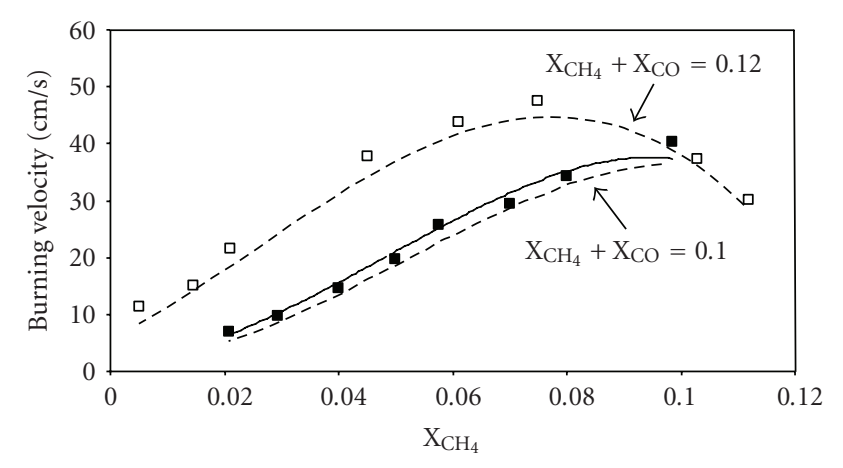

- Vagelopoulos \& Egolfopoulos [7]

- - RUN1DL-C1 chemistry

— PREMIX-GRIMECH

FIGURE 1: Unstretched burning velocities of $\mathrm{CH}_{4}$ - $\mathrm{CO} /$ air mixtures at 1 bar pressure, $300 \mathrm{~K}$.

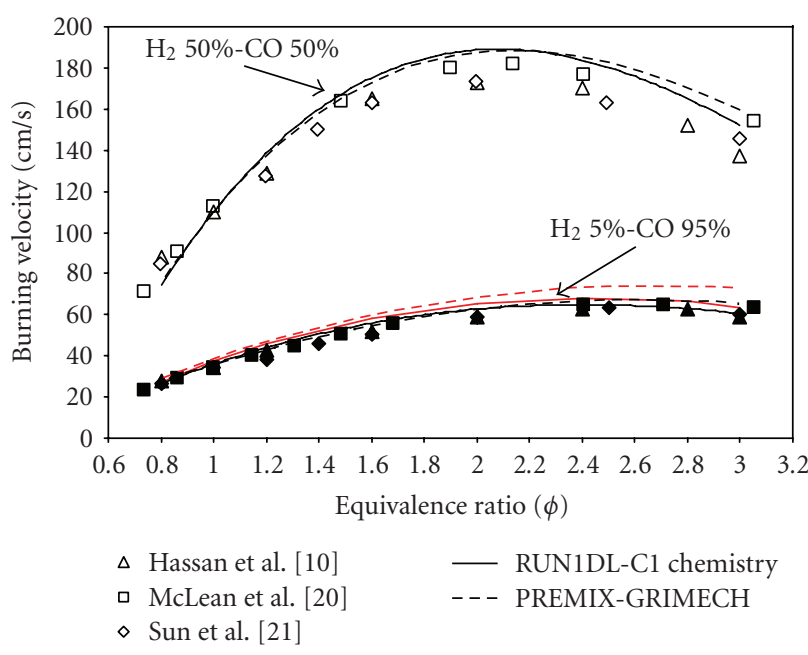

Figure 2: Unstretched burning velocities of $\mathrm{H}_{2}$-CO/air mixtures at 1 bar pressure, $300 \mathrm{~K}$. Red lines indicate predictions without inclusion of thermal diffusion effect.

3.0 for freely propagating planar flames. The comparisons with experiments are quite good and RUN1DL predicts peak burning velocities at the same equivalence ratios as in the experiments.

In Figure 2, results of computations with and without thermal diffusion using RUN1DL and PREMIX for $\mathrm{H}_{2}$ (5\%)-CO (95\%) is shown. Bongers and de Goey [22] have shown that for light species like hydrogen, taking the Soret effect or thermal diffusion into account makes a difference of about $10 \%$ in the predicted burning velocity. Figure 2 shows that the inclusion of thermal diffusion caused burning velocity to reduce by $5 \%$ for RUN1DL simulations and $8 \%$ for PREMIX simulations for $5 \% \mathrm{H}_{2}-95 \%$ CO mixture. Hence, for correct simulation of flame propagation in a fuel containing hydrogen the inclusion of thermal diffusion is essential.

The results presented in the foregoing sections indicate clearly that the $\mathrm{C} 1$ mechanism of Warnatz et al. [15] is able to predict burning velocities of single fuels and fuel mixtures containing $\mathrm{CO}, \mathrm{H}_{2}$, and $\mathrm{CH}_{4}$ burning in air at atmospheric pressure within the experimental uncertainties in almost all the cases presented. The percentage difference between experimental data and simulation results using Warnatz $\mathrm{C} 1$ mechanism was less than $5 \%$ for methane-air and hydrogenair flames. The percentage difference was less than about $10 \%$ for binary fuel mixtures. Therefore, this mechanism was used for all subsequent computations presented in this paper. Thermal diffusion effects have been included in the results presented hereafter.

\section{RESULTS AND DISCUSSION}

\subsection{Burning velocities and Markstein numbers of producer gas-air flames}

The following sections present computational results for ternary gaseous fuel mixtures of $\mathrm{CO}, \mathrm{H}_{2}$, and $\mathrm{CH}_{4}$ with diluents $\mathrm{CO}_{2}$ and $\mathrm{N}_{2}$. Table 2 gives three compositions of producer gas [23], obtained from different feed stocks using different kinds of biomass gasification technology. A brief perusal of Table 2 indicates that PG2 has nearly the same relative proportions of fuel constituents as PG1. The diluents in PG2, which again are in the same relative proportions of $\mathrm{CO}_{2}$ and $\mathrm{N}_{2}$ as in PG1, are nearly 50\% more than those in PG1. PG3 has nearly the same amount of total diluents as PG1, while the hydrogen content in PG3 is about $40 \%$ more than that in PG1. Thus, in the following sections, a comparison of PG1 and PG2 could be expected to bring out the effect of diluents, whereas a comparison of PG1 and PG3 could be expected to illustrate the effect of hydrogen content.

Computational investigations of outwardly propagating spherical flames were carried out for these producer gas mixtures at 1 bar and $300 \mathrm{~K}$ using Warnatz $\mathrm{C} 1$ mechanism. Two features were intended to be studied: (i) the effect of composition on unstretched burning velocity and (ii) the sensitivity of the laminar burning velocity to stretch.

Figure 3 shows the unstretched burning velocity as a function of equivalence ratio for the different producer gas compositions, obtained using linear extrapolation of stretched burning velocity data to zero stretch. Clearly, the laminar burning velocity increases with increase in hydrogen content in the fuel at any equivalence ratio. For PG2, the burning velocity peak occurs at an equivalence ratio of 1.1. With higher hydrogen content, the occurrence of peak shifts to higher values of equivalence ratio. For PG1, it occurs at an equivalence ratio of 1.3 , whereas for PG3 (31\% hydrogen), it occurs at an equivalence ratio of about 1.4. It can be concluded from these observations that laminar burning velocity of producer gas is strongly influenced by the hydrogen content in the mixture.

Figure 4 shows predicted Markstein numbers over a range of equivalence ratios for different producer gas compositions. As outlined in Section 3, Markstein length $(L)$ was obtained in the process of linear extrapolation of stretched burning velocity data to zero stretch for the simulations of spherically expanding flames considered here. For the calculation of Markstein number $\left(=L / \delta_{D}\right)$, the characteristic flame thickness, $\delta_{D}\left(=D_{u} / S_{L}\right)$, was based on the diffusivity 
TABLE 2: Gas compositions of producer gas from different feed stocks.

\begin{tabular}{|c|c|c|c|c|c|c|c|}
\hline & \multirow{2}{*}{ Feed stock } & \multirow{2}{*}{ Gasifier used } & \multicolumn{5}{|c|}{ Gas composition (by \% volume) } \\
\hline & & & $\mathrm{H}_{2}$ & $\mathrm{CO}$ & $\mathrm{CH}_{4}$ & $\mathrm{CO}_{2}$ & $\mathrm{~N}_{2}$ \\
\hline Producer gas 1 (PG1) [23] & Wood chips & Downdraft & 22 & 22 & 4 & 10 & 42 \\
\hline Producer gas 2 (PG2) [23] & Rice Husk & Downdraft & 10 & 12 & 2 & 15 & 61 \\
\hline Producer gas 3 (PG3) [24] & Wood chips & Two-stage & 31 & 18 & 1 & 15 & 35 \\
\hline
\end{tabular}

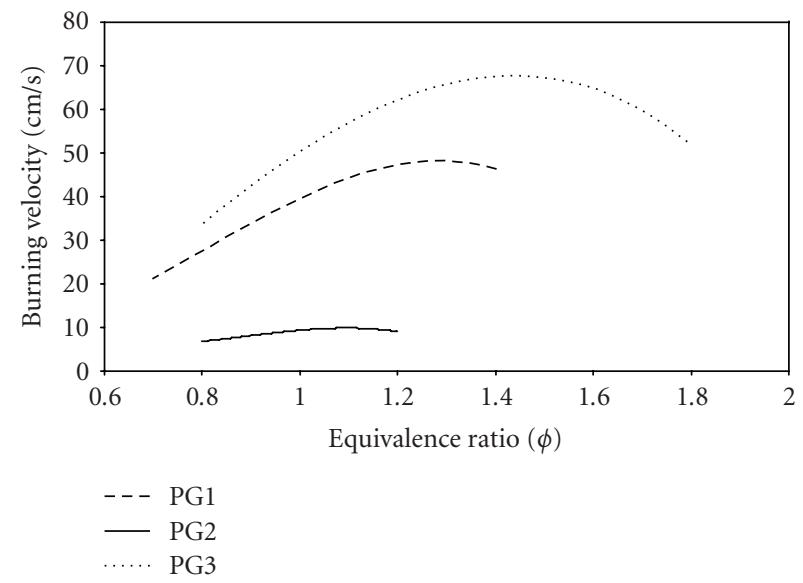

FIGURE 3: Unstretched burning velocity as a function of equivalence ratio for producer gas-air mixtures at 1 bar and $300 \mathrm{~K}$.

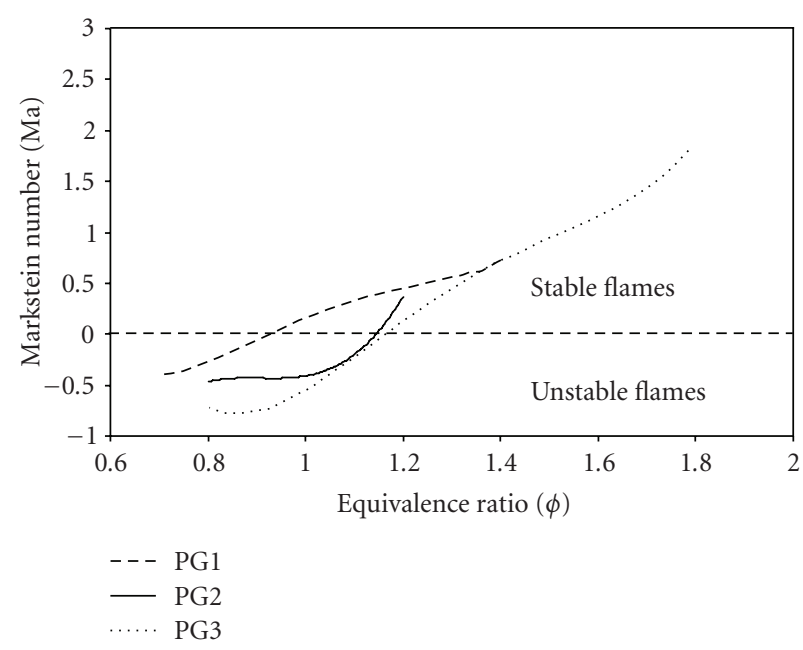

FIgURE 4: Predicted Markstein numbers for producer gas as function of equivalence ratio.

$\left(D_{u}\right)$ of hydrogen into nitrogen. It can be seen from Figure 4 that for lean and moderately rich mixtures of all three producer gases, the Markstein number is negative.

If $\mathrm{Ma}<0$, the flame is in the preferential diffusion instability regime, and if $\mathrm{Ma}>0$, it is in the stable regime [25]. If $\mathrm{Ma}=0$, the flame is neutrally stable and $S_{L}=S_{L \infty}$ at all values of stretch rate. The flame can be seen to be neutrally stable at $\phi \approx 0.9$ for PG1, and at $\phi \approx 1.15$ for PG2 and PG3. Comparing the stability behaviour of PG1 and PG3, we find that PG1 exhibits stability with respect to preferential diffusion for a wider range of equivalence ratio compared to PG3. This could be attributed to the higher hydrogen content in PG3. This behaviour was also observed by Hassan et al. [10]; with an increase of $\mathrm{H}_{2}$ fraction (by volume) from $3 \%$ to $50 \%$ in a binary fuel mixture of $\mathrm{H}_{2}$-CO, the neutral stability shifts from $\phi \approx 1.1$ to 1.6 , showing the effect of hydrogen content in fuel on preferential diffusion stability.

A comparison of the preferential diffusion stability characteristics of PG1 and PG2 shows that PG2 is more unstable, and this can be attributed to the larger amount of diluents in PG2. Kwon and Faeth [13] have shown a similar result for $\mathrm{H}_{2}-\mathrm{O}_{2}-\mathrm{Ar}$ mixtures: at $\phi=0.6$, with variation of $\mathrm{O}_{2} /\left(\mathrm{O}_{2}+\mathrm{Ar}\right)$ from 0.36 to $0.21, \mathrm{H}_{2} / \mathrm{O}_{2} / \mathrm{Ar}$ mixtures also showed a transition from stable to unstable condition. Also Qiao et al. [26] have shown that for $\mathrm{H}_{2}$-air mixtures at $\phi=1$ an increase in dilution with $\mathrm{Ar}, \mathrm{N}_{2}$, or $\mathrm{CO}_{2}$ from $0 \%-40 \%$ results in transition from stable to unstable condition. Taylor [19] found that with dilution of $\mathrm{H}_{2}$-air mixture with nitrogen from $0-60 \%$, Markstein number changed from positive to negative values, signifying transition.

\subsection{Extraction of effective Lewis number of mixture}

Preferential diffusion stability characteristics can be explained based on the effective Lewis number of the mixture. However, the calculation of effective Lewis number for a multicomponent fuel mixture is not as straightforward as for a pure fuel-air mixture such as $\mathrm{CH}_{4}$-air. Chung and Law [27] presented an expression for computing the deviation in burnt gas temperature from the stretch-free adiabatic flame temperature due to the simultaneous presence of preferential diffusion and stretch. Based on this expression, the effective Lewis number can be written in terms of the actual burnt gas temperature $\left(T_{b}\right)$ and stretch-free burnt gas temperature $\left(T_{b}^{0}\right)$ as

$$
\frac{T_{b}}{T_{b}^{0}}=1+\mathrm{Ka}\left(\frac{1}{\mathrm{Le}_{\mathrm{eff}}}-1\right) \Longrightarrow \mathrm{Le}_{\mathrm{eff}}=\frac{1}{(1 / \mathrm{Ka})\left(T_{b} / T_{b}^{0}-1\right)+1} .
$$

At every time step in the simulation the burnt gas temperature $\left(T_{b}\right)$ is obtained. The value of $T_{b}^{0}$, the adiabatic flame temperature under equilibrium assumption, was determined using STANJAN [28]. After extensive study for various mixtures, it was found that $T_{b} / T_{b}^{0}$ varies linearly with $\mathrm{Ka}$ for $\mathrm{Ka}<0.05$ and the intercept is very close to unity. Effective Lewis number ( Le $_{\text {eff }}$ ) values obtained using (4) for PG3 at different equivalence ratios are tabulated in Table 3. It has to be mentioned here that in the absence of an expression for an effective Lewis number in terms of individual reactant 
TABLE 3: Effective Lewis number ( Le $_{\text {eff }}$ ) of PG3 mixture at different equivalence ratios.

\begin{tabular}{ccccc}
\hline$\phi$ & Ka & Le eff $_{\text {er }}$ & Ma & Stability \\
\hline 0.8 & 0.1 & 0.69 & -0.72 & Unstable \\
1.1 & 0.05 & 0.82 & -0.57 & Unstable \\
1.2 & 0.03 & 1.02 & 0.20 & Stable \\
1.8 & 0.1 & 1.14 & 1.86 & Stable \\
\hline
\end{tabular}

Lewis numbers for the multicomponent mixtures studied in this work, the above semiempirical approach has been used to arrive at an effective Lewis number from the observed linear variation of $T_{b}$ with stretch. The effective Lewis number that obtained is independent of stretch.

At $\phi=0.8$ and $\phi=1.1$, where Le eff $_{\text {is }}$ less than unity, we observe that the Markstein number (Ma) is negative indicating unstable flames. At $\phi=1.2$ and $\phi=1.8$, where Le $_{\text {eff }}$ is greater than unity, the Markstein number is positive indicating stable flames. Here, it can be clearly seen that $\mathrm{Le}_{\text {eff }}$ can be used as the parameter based on which one can characterise the stability of the flame for the mixture. However, the computation of either of the parameters indicating flame stability, the effective Lewis number, and the Markstein number, needs the results of computations of the flame propagation, that is, these parameters cannot be calculated from the known values of unburnt gas properties and composition.

\subsection{Parametric study on the effect of composition on burning velocity and flame stability}

Although a comparison of PG1, PG2, and PG3 demonstrated the effects of diluent content and hydrogen content in the fuel mixture on the burning velocity and flame stability, a more systematic study is necessary to be able to attribute the behaviour of the flame to changes in the fuel composition. Hence, a parametric study was carried out to quantify the effect of fuel composition on the burning velocity and flame stability characteristics of producer gas-air flames. The simulations were carried out using RUN1DL with variation in volumetric percentage of fuel components, namely, $\mathrm{CH}_{4}$, $\mathrm{H}_{2}$, and $\mathrm{CO}$ in the producer gas, keeping $\mathrm{N}_{2}$ at $42 \%$ and $\mathrm{CO}_{2}$ at $10 \%$. Amongst fuel components, $\mathrm{CH}_{4}$ was kept at 0 and $12 \%$, and $\mathrm{H}_{2}$ and $\mathrm{CO}$ were varied in steps of 12 such that total fuel composition was $48 \%$. Each gas mixture was simulated for spherical flame propagation over a range of equivalence ratios at a constant pressure of 1 bar and unburnt gas temperature of $300 \mathrm{~K}$. The results of this exercise bring out clearly the effect of each fuel constituent on the combustion behaviour of the mixture.

In Figure 5 burning velocities of mixtures with $0 \% \mathrm{CH}_{4}$ are plotted as a function of equivalence ratio to demonstrate the effect of relative proportions of $\mathrm{CO}$ and $\mathrm{H}_{2}$. In these mixtures, $\mathrm{H}_{2}$ and $\mathrm{CO}$ were varied between 12 to $48 \%$ by volume, and the equivalence ratio was varied in the range 0.8-2.0. The value of the peak burning velocity increases by as much as $200 \%$ with an increase in hydrogen content from $12 \%$ to $48 \%$. This behaviour was also shown in Figure 3,

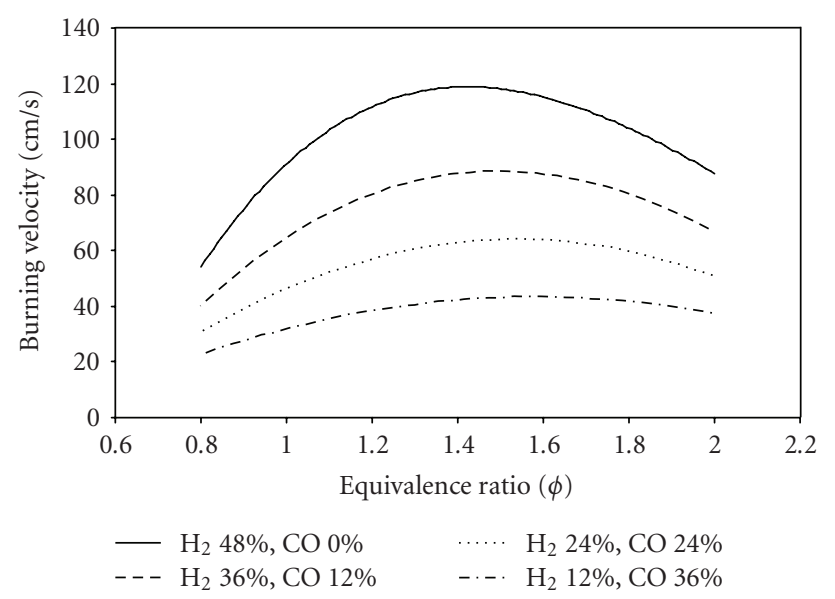

FIGURE 5: Unstretched burning velocity with $0 \% \mathrm{CH}_{4}$ as function of equivalence ratio at 1 bar pressure and $300 \mathrm{~K}$.

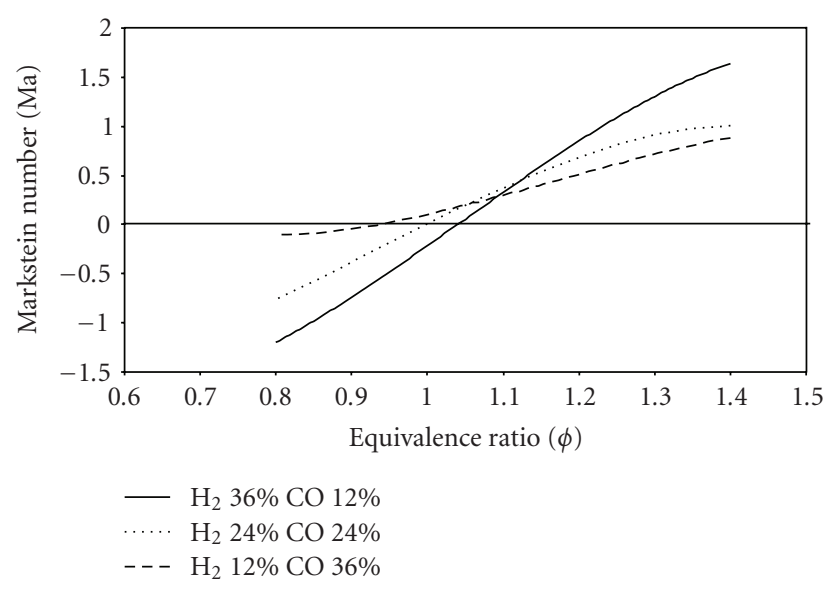

FIgure 6: Predicted Markstein numbers with $0 \% \mathrm{CH}_{4}$ as function of equivalence ratio at 1 bar pressure and $300 \mathrm{~K}$.

where PG3 was shown to have a much higher burning velocity than PG1. From the consistency between the two cases, it can be concluded that the higher burning velocity of PG3 was clearly owing to its higher hydrogen content.

It can also be observed that the peak burning velocity shifts from $\phi=1.6$ for $12 \% \mathrm{H}_{2}$ to $\phi=1.4$ for $48 \% \mathrm{H}_{2}$. With increase in $\mathrm{CO}$ content, $\mathrm{H}_{2}$-CO mixtures $[10,21]$ show peak burning velocities at equivalence ratios greater than 2 , while pure hydrogen shows a peak at $\phi=1.8[5,13]$. Thus, an increase in $\mathrm{CO}$ and a decrease in $\mathrm{H}_{2}$ content in the mixture result in the shift of the burning velocity peak toward a higher value of $\phi$.

Predicted Markstein numbers for different fuel compositions are shown in Figure 6. With the increase in $\mathrm{H}_{2}$ percentage by volume in the fuel from $12 \%$ to $36 \%$, the equivalence ratio at which stable to unstable transition occurs shifts from $\phi=0.9$ to $\phi=1.05$. This shows that the increase of hydrogen in fuel causes a shift in the threshold equivalence ratio for stability of laminar flames to higher values. This finding is in consonance with stability 


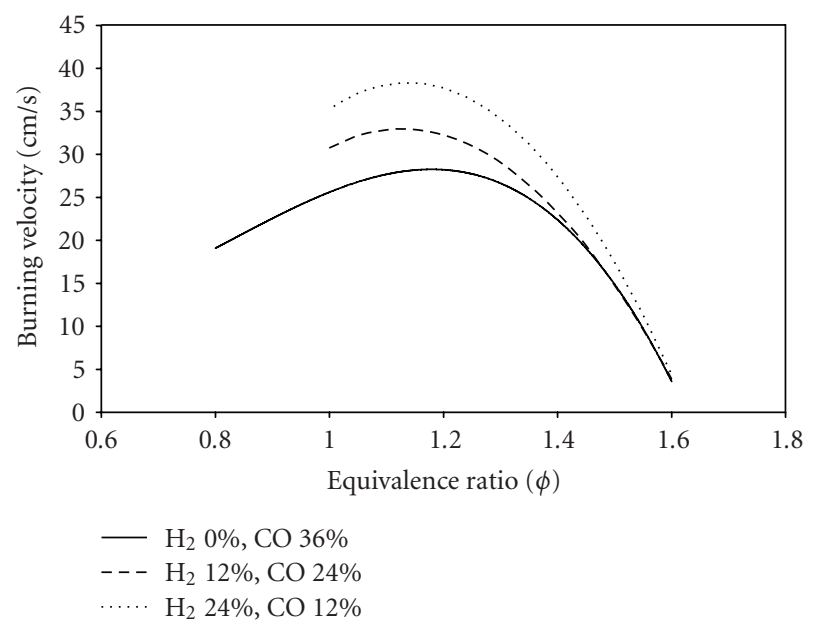

FIGURE 7: Unstretched burning velocity with $12 \% \mathrm{CH}_{4}$ as function of equivalence ratio at 1 bar pressure and $300 \mathrm{~K}$.

characteristics observed for producer gas mixtures 1 and 3 as discussed before.

In Figure 7, burning velocities of mixtures with $12 \% \mathrm{CH}_{4}$ by volume and the remaining $36 \%$ comprising $\mathrm{H}_{2}$ and $\mathrm{CO}$ are plotted over a range of equivalence ratios. The peak occurs at $\phi=1.2$ for $0 \% \mathrm{H}_{2}$ and shifts to 1.1 for $24 \% \mathrm{H}_{2}$. It can be noticed that the burning velocity values for all compositions for rich mixtures vary within a narrow range. The steep decrease in burning velocity from $23 \mathrm{~cm} / \mathrm{s}\left(12 \% \mathrm{H}_{2}\right.$ and $24 \%$ CO mixture) at $\phi=1.4$ to $3 \mathrm{~cm} / \mathrm{s}$ at $\phi=1.6 \mathrm{can}$ be seen in sharp contrast with Figure 5. The principal difference between Figures 5 and 7 is the presence of $12 \% \mathrm{CH}_{4}$ in the latter. It is interesting to note that the presence of even a small quantity of $\mathrm{CH}_{4}$ restricts the range of equivalence ratios over which the mixture can burn. Also, a comparison of the values of burning velocity for the $12 \%$ and $24 \% \mathrm{H}_{2}$ cases in the two figures shows that replacing $\mathrm{CO}$ with $\mathrm{CH}_{4}$ results in a sharp decrease in burning velocity values in the rich side, especially at equivalence ratios exceeding 1.2.

\section{CONCLUSIONS}

The effects of stretch and composition on laminar burning velocities and stability of multicomponent mixtures like producer gas were studied computationally using outwardly propagating spherical flames. The major conclusions of the study are as follows.

(1) Three reaction mechanisms, Warnatz C1 chemistry mechanism, C1-C2 chemistry mechanism, and GRI $\mathrm{MECH} 3.0$ were tested for prediction against experimental results of binary mixtures of $\mathrm{H}_{2}$ - $\mathrm{CO}$ and $\mathrm{CH}_{4}$-CO. Warnatz $\mathrm{Cl}$ chemistry is the smallest mechanism considered in this paper, which was found to predict burning velocities better than other mechanisms for all the tested fuels at 1 bar and $300 \mathrm{~K}$. This mechanism is used for prediction of burning velocities of producer gas in this paper.
(2) The variation in burning velocity when the Soret effect is accounted for is at least $5 \%$ even with $5 \%$ of hydrogen (by volume) in the binary fuel of $\mathrm{H}_{2}$-CO. Hence, inclusion of thermal diffusion for fuels containing light species like hydrogen is very important.

(3) This study indicates that the effect of hydrogen enhances the burning velocity and lowers the equivalence ratio at the peak burning velocity. It also shows that increase in dilution promotes onset of instability.

(4) An effective Lewis number was calculated from change in temperature of flames due to simultaneous presence of stretch and preferential diffusion. An effective Lewis number less than unity indicated unstable flames. Stable flames were obtained for Lewis numbers greater than unity in the cases studied.

(5) A parametric study of the effect of composition on burning velocity for ternary mixtures shows the following.

(a) The increase in burning velocity is dictated by the amount of hydrogen present. The extent of increase is limited by the presence of methane. Methane also limits the range of values of equivalence ratio over which the mixture burns.

(b) The equivalence ratio at which the peak burning velocity occurs shifts toward lower values with increase in hydrogen content and decrease in $\mathrm{CO}$.

\section{ACKNOWLEDGMENTS}

The authors are grateful to Professor B. Rogg and Dr. Wang, Ruhr-Universitat Bochum for providing them with the RUN1DL code which is used in this work.

\section{REFERENCES}

[1] I. Wender, "Reactions of synthesis gas," Fuel Processing Technology, vol. 48, no. 3, pp. 189-297, 1996.

[2] T. Hasegawa, M. Sato, and T. Nakata, "A study of combustion characteristics of gasified coal fuel," Journal of Engineering for Gas Turbines and Power, vol. 123, no. 1, pp. 22-32, 2001.

[3] D. P. Mishra, P. J. Paul, and H. S. Mukunda, "Stretch effects extracted from propagating spherical premixed flames with detailed chemistry," Combustion and Flame, vol. 99, no. 2, pp. 379-386, 1994.

[4] D. Bradley, P. H. Gaskell, and X. J. Gu, "Burning velocities, Markstein lengths, and flame quenching for spherical methane-air flames: a computational study," Combustion and Flame, vol. 104, no. 1-2, pp. 176-198, 1996.

[5] C. J. Sun, C. J. Sung, L. He, and C. K. Law, "Dynamics of weakly stretched flames: quantitative description and extraction of global flame parameters," Combustion and Flame, vol. 118, no. 1-2, pp. 108-128, 1999.

[6] R. J. Kee, J. F. Grcar, M. D. Smooke, J. A. Miller, and E. Meeks, "A fortran program for modelling steady laminar onedimensional premixed flames," Tech. Rep. SAND85-8240, Sandia National Laboratories, Albuquerque, NM, USA, 1993. 
[7] C. M. Vagelopoulos and F. N. Egolfopoulos, "Laminar flame speeds and extinction strain rates of mixtures of carbon monoxide with hydrogen, methane, and air," Proceedings of the Combustion Institute, vol. 25, pp. 1317-1323, 1994.

[8] C. M. Vagelopoulos and F. N. Egolfopoulos, "Direct experimental determination of laminar flame speeds," Proceedings of the Combustion Institute, vol. 27, pp. 513-519, 1998.

[9] L. K. Tseng, M. A. Ismail, K. T. Aung, and G. M. Faeth, "Laminar burning velocities and Markstein numbers of hydrocarbon/air flames," Combustion and Flame, vol. 102, pp. 526-530, 1995.

[10] M. I. Hassan, K. T. Aung, and G. M. Faeth, "Properties of laminar premixed $\mathrm{CO} / \mathrm{H}_{2}$ /air flames at various pressures," Journal of Propulsion and Power, vol. 13, no. 2, pp. 239-245, 1997.

[11] K. T. Aung, M. I. Hassan, and G. M. Faeth, "Flame stretch interactions of laminar premixed hydrogen/air flames at normal temperature and pressure," Combustion and Flame, vol. 109, no. 1-2, pp. 1-24, 1997.

[12] M. I. Hassan, K. T. Aung, and G. M. Faeth, "Measured and predicted properties of laminar premixed methane/air flames at various pressures," Combustion and Flame, vol. 115, no. 4, pp. 539-550, 1998.

[13] O. C. Kwon and G. M. Faeth, "Flame/stretch interactions of premixed hydrogen-fueled flames: measurements and predictions," Combustion and Flame, vol. 124, no. 4, pp. 590-610, 2001.

[14] B. Rogg and W. Wang, "RUN1DL: the laminar flamelet codeuser manual," 8th revised printing, 1995.

[15] J. Warnatz, U. Maas, and R. W. Dibble, Combustion: Physical and Chemical Fundamentals, Modelling and Simulation, Experiments, Pollutant Formation, Springer, Berlin, Germany, 2nd edition, 1999.

[16] M. Frenklach, C. T. Bowman, G. P. Smith, and W. C. Gardiner, Version 3.0, 1999, http://www.me.berkeley.edu/gri-mech.

[17] A. A. Konnov, "Detailed reaction mechanism for small hydrocarbons combustion," Release 0.5, 2000, http://homepages .vub.ac.be/ akonnov.

[18] M. V. Petrova and F. A. Williams, "A small detailed chemicalkinetic mechanism for hydrocarbon combustion," Combustion and Flame, vol. 144, no. 3, pp. 526-544, 2006.

[19] S. C. Taylor, "Burning Velocity and the influence of flame stretch," Ph.D. thesis, University of Leeds, Leeds, UK, 1991.

[20] I. C. McLean, D. B. Smith, and S. C. Taylor, "The use of carbon monoxide/hydrogen velocities to examine the rate of the $\mathrm{CO}+\mathrm{OH}$ reaction," Proceedings of the Combustion Institute, vol. 25, pp. 749-757, 1994.

[21] H. Sun, S. I. Yang, G. Jomaas, and C. K. Law, "Highpressure laminar flame speeds and kinetic modeling of carbon monoxide/hydrogen combustion," Proceedings of the Combustion Institute, vol. 31, pp. 439-446, 2007.

[22] H. Bongers and L. P. H. de Goey, "The effect of simplified transport modelling on the burning velocity of laminar premixed flames," Combustion Science and Technology, vol. 175, no. 10, pp. 1915-1928, 2003.

[23] P. J. Paul, S. Dasappa, H. S. Mukunda, and N. K. S. Rajan, Biomass to Energy, the Science and Technology of the IISc Bioenergy System, Advanced Bioresidue Energy Technologies Society, Indian Institute of Science, Bangalore, India, 2003.

[24] A. Jesper, K. J. Torben, U. B. Henriksen, and B. Gobel, CO and PAH Emissions from Engines Operating on Biomass Producer Gas, Department of Mechanical Engineering, Technical University of Denmark, Lyngby, Denmark, 2003.
[25] C. K. Law, Combustion Physics, Cambridge University Press, Cambridge, UK, 2006.

[26] L. Qiao, C. H. Kim, and G. M. Faeth, "Suppression effects of diluents on laminar premixed hydrogen/oxygen/ nitrogen flames," Combustion and Flame, vol. 143, no. 1-2, pp. 79-96, 2005.

[27] S. H. Chung and C. K. Law, "An Integral analysis of the structure and propagation of stretched premixed flames," Combustion and Flame, vol. 72, pp. 325-336, 1988.

[28] W. C. Reynolds, "The element potential method for chemical equilibrium analysis: implementation in the interactive program STANJAN," Tech. Rep., Department of Mechanical Engineering, Stanford University, Stanford, Calif, USA, 1986. 

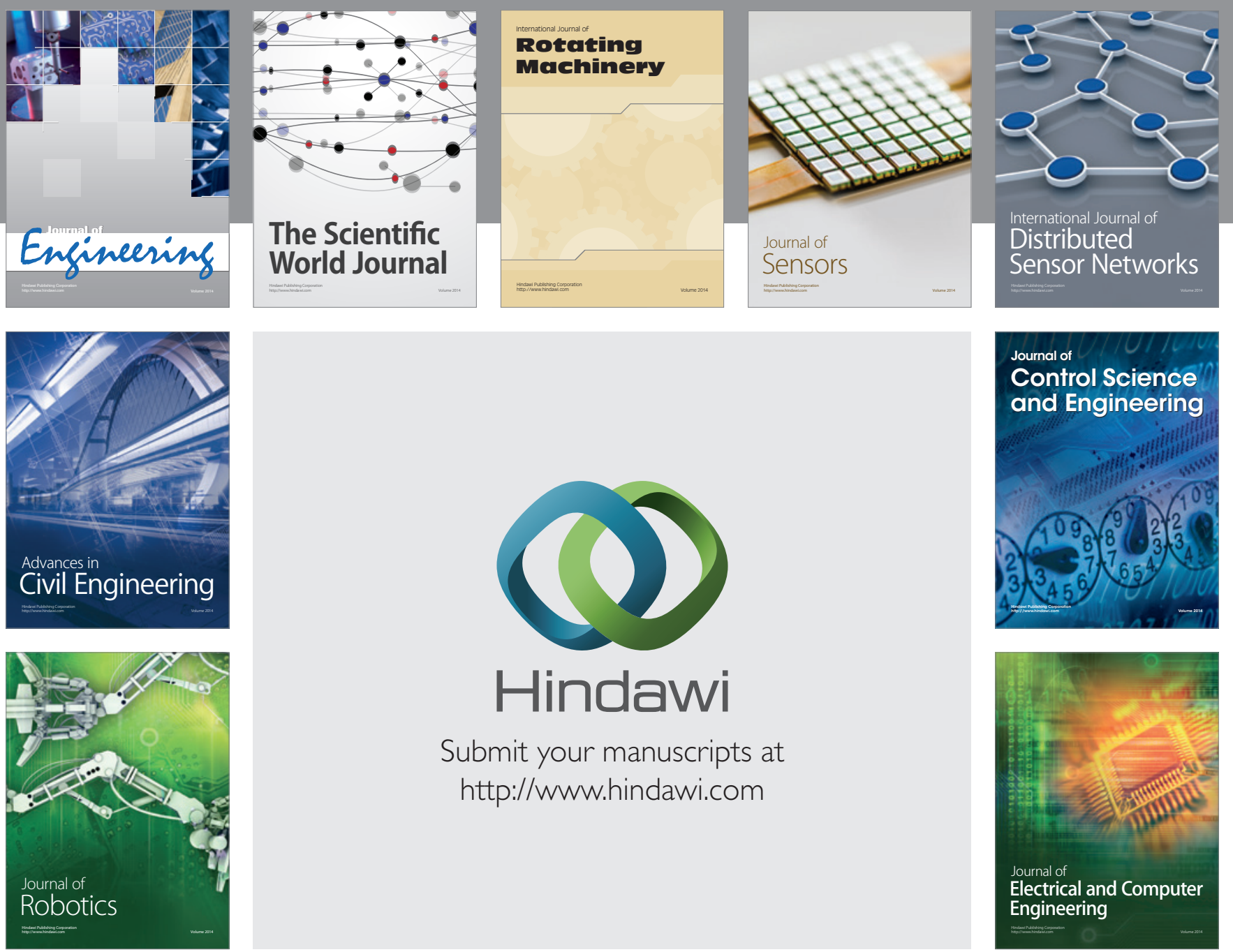

Submit your manuscripts at

http://www.hindawi.com
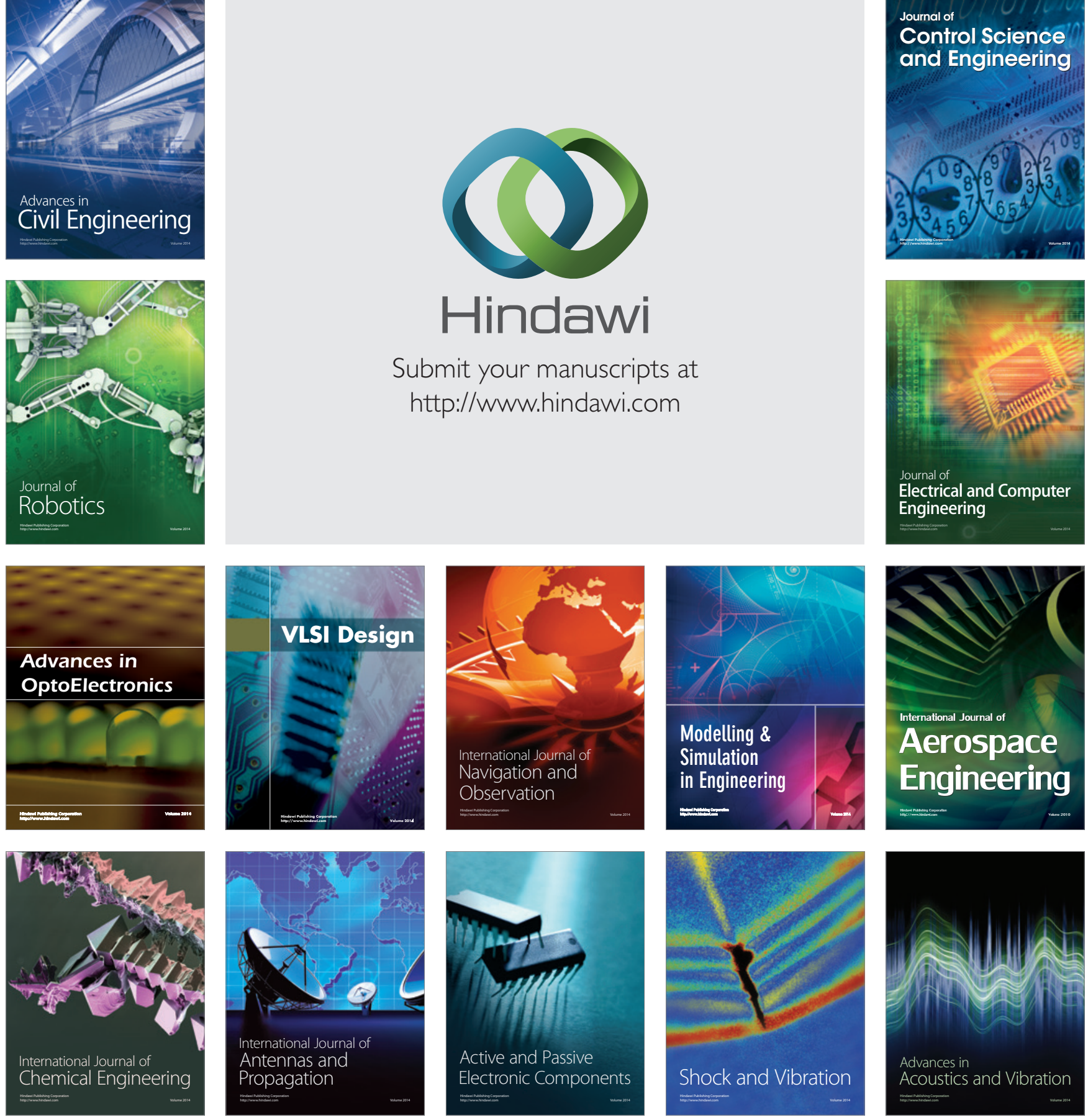